\title{
Investigating dimensionality and measurement bias of DSM-5 Alcohol Use Disorder in a representative sample of the largest metropolitan area in South America
}

\author{
João Mauricio Castaldelli-Maia ${ }^{1,2,3}$, Yuan-Pang Wang ${ }^{1}$, Guilherme Borges ${ }^{4}$, Camila M. \\ Silveira $^{1,2}$, Erica R. Siu ${ }^{1}$, Maria C. Viana ${ }^{5}$, Arthur G. Andrade ${ }^{1,2}$, Silvia S. Martins ${ }^{6, \dagger}$, and \\ Laura H. Andrade ${ }^{1, \dagger}$ \\ ${ }^{1}$ Section of Psychiatric Epidemiology - LIM 23, Department and Institute of Psychiatry, University \\ of São Paulo Medical School, São Paulo, Brazil, 05403 \\ ${ }^{2}$ Interdisciplinary Group of Studies on Alcohol and Drugs, Department and Institute of Psychiatry, \\ University of São Paulo Medical School, São Paulo, Brazil, 05403 \\ ${ }^{3}$ Department of Neuroscience, Medical School, Fundação do ABC, Santo André, SP, Brazil, \\ 09060
}

${ }^{4}$ National Institute of Psychiatry and Metropolitan Autonomous University, Mexico City, México, 14370

${ }^{5}$ Department of Social Medicine and Post-Graduate Program in Public Health, Federal University of Espírito Santo, Vitória, ES 29040, Brazil

${ }^{6}$ Department of Epidemiology, Columbia University Mailman School of Public Health, New York, NY, USA, 10032

\section{Abstract}

Corresponding author: João Mauricio Castaldelli-Maia, Address: Núcleo de Epidemiologia Psiquiátrica (NEP-LIM 23) - Rua Dr

Ovídio Pires de Campos, 785, 05403-903, São Paulo, SP, Brazil. Phone: + 551126616976 / jmcmaia2@gmail.com.

Dr. L. Andrade and Dr. S. Martins share senior authorship of this manuscript.

${ }^{2}$ Supplementary material can be found by accessing the online version of this paper at http://dx.doi.org and by entering doi:...

Contributors

Authors JMC-M, Y-PW, SSM and LHGA designed the study. MCV and LHGA wrote protocol, and created the databank. Authors JMC-M, GB, CMS, ERS, AGA, LHGA, and SSM managed the literature searches and summaries of previous related work. JMC-M and SSM undertook the statistical analysis. Author JMC-M, Y-PW, LHGA and SSM wrote the first draft of the manuscript. All authors contributed to and have approved the final manuscript.

Supplementary material can be found by accessing the online version of this paper at http://dx.doi.org and by entering doi:...

Conflict of Interest

Dr. Castaldelli-Maia receives Pfizer Independent Grant for Learning and Change (IGLC) managed by Global Bridges (Healthcare Alliance for Tobacco Dependence Treatment) hosted at Mayo Clinic, to support free smoking cessation treatment training in addiction/ mental health care units in Brazil (grant IGLC 13513957), which had no relationship with the present study. Dr. Martins is currently a consultant for Purdue Pharma to conduct secondary data analyses of U.S. data unrelated to this project. Dr. A. G. Andrade and Dr. Silveira are respectively Executive President and Coordinator of Center for Information on Health and Alcohol (CISA), which had no funding relationship with this project. All other authors have no conflicts of interest.

Publisher's Disclaimer: This is a PDF file of an unedited manuscript that has been accepted for publication. As a service to our customers we are providing this early version of the manuscript. The manuscript will undergo copyediting, typesetting, and review of the resulting proof before it is published in its final citable form. Please note that during the production process errors may be discovered which could affect the content, and all legal disclaimers that apply to the journal pertain. 
Background-Given the recent launch of a new diagnostic classification (DSM-5) for alcohol use disorders (AUD), we aimed to investigate its dimensionality and possible measurement bias in a non-U.S. sample.

Methods-The current analyses were restricted to 948 subjects who endorsed drinking at least 1 drink per week in the past year from a sample of 5,037 individuals. Data came from São Paulo Megacity Project (which is part of World Mental Health Surveys) collected between 2005-2007. First, exploratory factor analysis (EFA) was carried out to test for the best dimensional structure for DSM-5-AUD criteria. Then, item response theory (IRT) was used to investigate the severity and discrimination properties of each criterion of DSM-5-AUD. Finally, differential criteria functioning (DCF) were investigated by sociodemographics (income, gender, age, employment status, marital status and education). All analyses were performed in Mplus software taking into account complex survey design features.

Results-The best EFA model was a one-dimensional model. IRT results showed that the criteria "Time Spent" and "Given Up" have the highest discrimination and severity properties, while the criterion "Larger/Longer" had the lowest value of severity, but an average value of discrimination. Only female gender had DCF both at criterion- and factor-level, rendering measurement bias.

Conclusion-This study reinforces the existence of a DSM-5-AUD continuum in the largest metropolitan area of South America, including subgroups that had previously higher rates of alcohol use (lower educational/income levels). Lower DSM-5-AUD scores were found in women.

\section{Keywords}

DSM-5; exploratory factor analysis; item response theory; differential item functioning; Latin America; megacities

\section{INTRODUCTION}

Despite the Fifth edition of Diagnostic and Statistical Manual of Mental Disorders (DSM-5) being a reality (American Psychiatric Association, 2013; Hasin et al., 2013) there is still the need to explore the stability of this new unidimensional construct of Alcohol Use Disorder (AUD) as well as the influence of sociocultural aspects of different populations on the indicators of this new construct (Agrawal et al., 2011; Hasin et al., 2013).

Most of the available studies have been carried out in the U.S. (Borges et al., 2010; Keyes et al., 2011; Kuerbis et al., 2013) using exploratory factor analysis (EFA) to validate the DSM-5 AUD unidimensional structure. Evidence from other cultures are much more limited (McBride et al., 2011; Mewton et al., 2011; Shmulewitz et al., 2010) and fewer included the full set of 11 criteria (since some lacked Craving, as defined by DSM-5 Alcohol Use Disorder criteria: Tolerance - as defined by either of the following: (a) a need for markedly increased amounts of alcohol to achieve Intoxication or desired effect; (b) markedly diminished effect with continued use of the same amount of alcohol; Withdrawal - as manifested by either of the following: (a) the characteristic withdrawal syndrome for alcohol (refer to Criteria A and B of the criteria sets for withdrawal from alcohol); (b) alcohol (or a closely related drug such as benzodiazepines) is used to relieve or avoid withdrawal criteria; Larger/Longer - alcohol is often used in larger amounts or over a longer period than was 
intended; Quit/Control - there is a persistent desire or unsuccessful efforts to cut down or control alcohol use; Time Spent - a great deal of time is spent in activities necessary to obtain alcohol, use alcohol, or recover from its effects; Activities Given Up - important social, occupational, or recreational activities are given up or reduced because of alcohol use;Physical/Psychological - alcohol use is continued despite knowledge of having a persistent or recurrent physical or psychological problem that is likely to have been caused or exacerbated by alcohol (e.g. continued drinking despite recognition that an ulcer was made worse by alcohol consumption); Neglect Roles - recurrent alcohol use resulting in a failure to fulfill major role obligations at work, school, or home (e.g., repeated absences or poor work performance elated to alcohol use; alcohol-related absences, suspensions, or expulsions from school; neglect of children or household); Social/Interpersonal -continued alcohol use despite having persistent or recurrent social or interpersonal problems caused or exacerbated by the effects of the alcohol (e.g., arguments with spouse about consequences of Intoxication, physical fights); Hazardous Use - recurrent alcohol use in situations in which it is physically hazardous (e.g., driving an automobile or operating a machine when impaired by alcohol use); Craving -a strong desire or sense of compulsion to take alcohol.). In addition to the EFA studies, several authors have called for verification of the distribution of the individual criterion within the unidimensional structure across studies and populations (Borges et al., 2010; Saha et al., 2006; Casey et al., 2012; Edwards et al, 2013). Item response theory (IRT) was used to explore the role of each of the criterion within this dimensional structure (Saha et al., 2006; Casey et al., 2012; Edwards et al, 2013). For instance, Saha et al. (2007) found that the DSM-IV criteria for alcohol abuse and dependence were disposed in a continuum, which contradicted the proposed hierarchy between the two diagnoses in DSM-IV. This opened a new strand of studies that have shown that the criteria may behave differently in different cultures and populations with different usage pattern (Saha et al., 2006; Casey et al., 2012; Edwards et al, 2013).

Also important is the use of differential criteria functioning (DCF) techniques to measure the direct effects of external factors (i.e., sociodemographic variables) that could potentially show evidence for measurement bias, a type of error in which a given variable can systematically generate false outcomes, in certain subgroups (Kuerbis et al., 2013; Casey et al., 2012; Rose et al., 2012; Srisurapanont et al., 2012). Current research has not been consistent in finding DCF and most of them were restricted to gender/age DCF (Casey et al., 2012; Rose et al., 2012; Srisurapanont et al., 2012). With the exception of Saha et al.'s study (2007), not other study has examined DCF at both criterion- and factor-level. Saha et al. (2007) state that DCF actually reflects invariance across subgroups just when observed criterion-level DCFs generate bias at the factor-level (scale).

In the present study, we aim to investigate the dimensionality and possible measurement bias of the new diagnostic classification (DSM-5) for alcohol use disorders (AUD) in a population-based sample of the largest metropolitan area in South America (São Paulo Metropolitan Area - SPMA). SPMA is a unique setting for this type of study for its socioeconomic diversity, with extremes of poverty existing side by side with wealth, resulting in social tension and high rates of urban violence (Viana et al., 2009), despite being the major financial and economic center of Brazil, with a Gross Domestic Product (GDP) corresponding to $16.7 \%$ of total Brazilian GDP.

Drug Alcohol Depend. Author manuscript; available in PMC 2016 July 01. 
We used data from the São Paulo Megacity Mental Health Survey (SPMHS), a crosssectional population-based study, designed to evaluate psychiatric morbidity in a representative sample in the general population, aged 18 years or more, living in this metropolitan area. In this dataset, the full set of the 11 DSM-5 AUD criteria has been collected, what allows us to use two-parameter item response theory (IRT) model to examination the threshold and discrimination parameter of each criterion of the DSM-5 latent alcohol use disorder construct. We also examined differential item functioning of each criterion and the latent construct of DSM-5 AUD across demographic subgroups.

\section{METHODS}

\subsection{Ethics Committee Approval}

The research and Ethics Committee of the University of São Paulo Medical School (Project number 792/03) approved the procedures for recruitment, obtaining informed consent, and protection of human subjects involved during field procedures of São Paulo Megacity Health Survey (SPMHS).

\subsection{Sample}

Respondents were selected through a multistage probabilistic process covering the 39 municipalities of São Paulo Metropolitan Area, without replacement. This survey is a crosssectional population-based study, designed to evaluate psychiatric morbidity in a representative sample in the general population, aged 18 years or more, living in the São Paulo Metropolitan Area (SPMA). The World Mental Health Study (WMHS) Composite International Diagnostic Interview (WMH-CIDI) of the World Health Organization, translated and adapted to Brazilian Portuguese (Viana et al., 2009), was used to assess the respondents. Data was collected between May 2005 and April 2007, by trained interviewers. The final sample had 5,037 individuals (response rate of 81.3\%). The current analyses were restricted to 948 subjects who endorsed drinking at least 1 drink per week in the past year. This sub-sample was chosen because of the low drinking levels in South America (Rehm et al., 2003; Castaldelli-Maia et al., 2014). If we have chosen the past-year drinking subsample, we would find a very low prevalence of DSM-5 AUD criteria endorsement.

\subsection{Interview}

The WMH-CIDI is comprised of clinical and non-clinical sections, which generate diagnoses based on DSM-IV and ICD-10. All respondents answered a socio-demographic module and the assessment modules of mood, anxiety, and impulse control disorders, along with substance abuse and suicidal behavior, considered nuclear disorders,. When a blind clinical re-appraisal of the Structured Clinical Interview for DSM-IV Axis I disorder (SCIDI) for last 12-month DSM-IV Disorders was performed in a probabilistic subsample of WMH respondents there was generally a good agreement between WMH-CIDI diagnoses and SCID diagnoses (Haro et al., 2006). Regarding specifically the SPMHS, there was good total classification accuracy (range: 76\%-99\%) and an area under the ROC curve around 0.7 for any disorder in the preliminary results of the clinical reappraisal study in the SPMHS with a probability subsample of 775 respondents, not included in the previous validation study (data available from the authors).

Drug Alcohol Depend. Author manuscript; available in PMC 2016 July 01. 


\subsection{Measures}

A series of questions derived from DSM-IV/ICD-10 alcohol abuse-harmful use/dependence criteria embedded in the WMH-CIDI were asked to the 948 subjects who endorsed drinking at least one drink per week in the past year (please see Supplementary File $1^{1}$ ).

Twelve individuals who did not answer these questions were excluded from the statistical analysis $(n=936)$. Eleven dichotomous variables matching the DSM-5 criteria were generated from these questions. The abbreviation of the names of the DSM-5 11 criteria was based upon previously published studies (Hasin et al., 2009; Shmulewitz et al., 2010; Saha et al., 2006; Castaldelli-Maia et al., 2014) as follows: Tolerance, Withdrawal, Larger/Longer, Quit/Control, Time Spent, Activities Given Up, Physical/Psychological, Neglect Roles, Social/Interpersonal, Hazardous Use and Craving.

\subsection{Statistical analysis}

All analyses were performed with Mplus version 7.3, using sampling weights and the complex survey design measures. Descriptive statistics were used to describe the sample. Specifically, counts and percentages were used to describe categorical variables.

2.5.1. Exploratory Factor Analysis (EFA)—First, EFA models were carried out. The decision on the most parsimonious model was made by the evaluation of Eigenvalue, Comparative Fit Index (CFI), Root Mean Squared Error of Approximation (RMSEA), Tucker-Lewis Index (TLI), and Standardized Root Mean Square Residual (SRMR), following a previous study that analyzed dimensional models for AUD (Borges et al., 2010).

2.5.2. Item Response Theory (IRT)—After the factor structure of DSM-5 AUD was investigated, IRT models were used to study the latent alcohol use disorder construct. IRT models analyze the relationship between the probabilities of an individual to endorse a certain response to an item. IRT analysis implemented in Mplus was used to derive two main parameters, the threshold and the discrimination parameters. The first refers to the 'severity' of a criterion (threshold), with high severity being those endorsed less frequently by respondents. The second parameter measures the ability of a criterion to discriminate respondents from low to high levels of the disorder continuum (slope). Item Characteristics Curves (ICC) and Item Information Curves (IIC) were produced. ICC shows severity (the point on the $\mathrm{x}$-axis where the $\mathrm{y}$-axis is 50\%), and discrimination (the slope of the curve at that point; Shmulewitz et al., 2010). Item Information Curves (IIC) show the amount of information the item provides across the latent trait continuum; the information peak is at item severity, and peak height is directly related to discrimination (Shmulewitz et al., 2010; Krueger et al., 2004). ICCs and IICs are shown to enable visualization of the relationships between item severity, discrimination/information, and the underlying latent trait.

2.5.3. Differential Criterion Functioning (DCF)—The following socio-demographic correlates were considered for measurement bias: gender (male as the referent category [RC]), age (RC: 35-54 years); education (RC: high education - 9 years of education or more); marital status (RC: currently married); employment status (RC: currently working/ studying); and household income, defined in categories (RC: high income - more than 7,050

Drug Alcohol Depend. Author manuscript; available in PMC 2016 July 01. 
US dollars/year) based on the respondent's household income per family member divided by the median income-per-family member in the entire sample. We used the four-step strategy recommended by Woods (2009), also used by Sacco et al. (2011) for Pathological Gambling criteria. First, (i) we tested preliminary models for each of the 11 DSM-5 AUD criteria, aiming at the identification of DCF free criteria. The DCF free criteria are those that do not have any direct effects from the socio-demographic correlates. In each preliminary model, all other 10 criteria were not tested for DCF. Criteria which were found DCF-free in these models become reference criteria (i.e., "anchors") in subsequent DCF testing (ii). A regression path from each of the grouping variables to each item was tested to analyze DCF, one by one. The difference in the responses by the groups (e.g., young adults), controlling for differences in the latent construct of AUD, is represented by this regression coefficient. Each criterion was tested in an independent model. DCF free reference items (which were not tested for DCF in the subsequent models) were considered those criteria found to have non-significant direct effects. In a next step (iii), the candidate criteria for DCF were individually tested in nested Multiple Indicators Multiple Causes (MIMIC) models. The MIMIC model is a special case of structural equation modeling that includes the relationships between: (i) the indicators (in this case, the 11 DSM-5 AUD criteria) and the factor, (ii) the factors and the covariates (in this case, the socio-demographic correlates); and (iii) the indicators and the covariates, called the direct criteria effects, because they indicate effects of the covariates on the indicators that are not mediated through the factors (Blanco et al., 2014). MIMIC models allow the researchers to analyze latent variables that are predicted by observed variables. Finally (iv), the criteria with significant DCF in nested models were used to construct a final MIMIC model.

\section{RESULTS}

Table 1 presents the prevalence of DSM-5 AUD criteria endorsement and the distribution of socio-demographic variables in the sample. There was a higher prevalence of men among past-year weekly alcohol users compared to the rest of the SPMHS sample (74\% versus $47 \%, \mathrm{p}<0.01$ ). We also found significant differences in age (younger), household income (high income), employment status (working/studying), and education.

Table 2 presents the results of EFA and IRT models. The one-dimensional (one-factor model) model was slightly better than the 2-factor model, because it obtained high loadings on all 11 criteria (>0.8), and generated the set of good fit EFA indices: Eigenvalue> 1.0; CFI and TLI $>0.95$; RMSEA $<0.05$; and SRMR $<0.08$. The fit indices for the 2 -factor model were also good, however, the value of the Eigenvalue dropped to a value well below 1.0 in the 2-factor model, not rising again with the increased number of factors (please see the Supplementary File 2 for more details ${ }^{2}$ ). The 2 -factor model also had a high factor correlation.

Figure 1 presents the Item Characteristics Curves (ICC) and Item Information Curves (IIC), which were produced by the IRT models. Within ICC and IIC, the criterion with the lowest value on the $50 \%$ point at the $\mathrm{x}$-axis was the Larger/Longer criterion. This denotes a lower severity of that specific criterion in relation to the other criteria. Moreover, the criterion with greater severity in the within ICC and IIC was the Given Up criterion. Other criteria that had

Drug Alcohol Depend. Author manuscript; available in PMC 2016 July 01. 
greater severity were Time Spent, Tolerance and Withdrawal. Furthermore, within ICC, the Time Spent criterion had the greater discrimination property. Discrimination is indicated by how steep the slope of the ICC is at the $50 \%$ point at the $\mathrm{x}$-axis. Other criteria with greater discrimination were Given Up and Physical/Psychological. The Hazardous Use criterion had the lowest discrimination property. The criterion which brings more information (IIC) is Time Spent followed by Given Up and Physical/Psychological (IIC). The criteria that bring less information (IIC) were Tolerance, Neglect Roles and Hazardous Use.

Table 3 shows the results of DCF models. Social/Interpersonal, Craving, Withdrawal, Quit/ Control, and Physical/Psychological were selected for the final DCF model, following the steps described in the methodology section. The variable Not working/not studying had direct effects (positive associations) on Social/Interpersonal and Withdrawal criteria. Young Adults variable (18-34 years) had direct effects (negative associations) on Craving and Withdrawal criteria. Within age, the variable Elderly ( $\geq 55$ years) also had direct effects, although positive, on Quit/Control and Physical/Psychological criteria. The variables Female and Low educational level (Up to 8 years) had only direct effect on Withdrawal and Quit/ Control, respectively. Therefore, the criterion with greater number of DCF was Withdrawal.

Figure 2 graphically summarizes the findings of the DCF models. Four direct effects from socio-demographic variables were found in the unidimensional factor, and 8 direct effects from these variables were found in any of the 11 criteria. The only category that had DCF both in criterion- and factor-level was female gender. In the elderly, the positive DCF found in Physical/Psychological and Quit/Control (criterion-level) was canceled at DSM-5 AUD (factor-level), in which we found a negative effect.

\section{DISCUSSION}

This was the first study to investigate dimensionality and possible measurement bias in the DSM-5 AUD in a large representative population based sample in Latin America. Studies like this, in large representative samples outside the United States, are important to test the functioning of this diagnosis, in different cultural settings (Shmulewitz et al., 2010; McBride et al., 2011; Mewton et al., 2011), given the differences that permeate the use of alcohol (Castaldelli-Maia and Bhugra, 2014), what is indeed the case of Brazil (Silveira et al., 2007, 2011, 2012; Castaldelli-Maia et al., 2013, 2014).

As expected, the one-factor model reached good fit indices in the EFA model, as found in other studies using the DSM-5 AUD in large representative samples in the U.S. (Keyes et al., 2011; Kuerbis et al., 2013), Australia (McBride et al., 2011; Mewton et al., 2011) and Israel (Shmulewitz et al., 2010). Keyes et al. (2011) and Mewton et al. (2011) found a good onedimensional structure with high values of loadings (>0.6) for all DSM-5 AUD. In these studies (Keyes et al., 2011; Mewton et al., 2011), the Craving criterion also dovetailed with other criteria, reaching a loading value ( 0.87 and 0.85 respectively) very similar to that found in our study. Kuerbis et al. (2013) used a representative sample of individuals aged 50 or older in the U.S. to confirm the one-dimensional model for DSM-5 AUD. They also found high levels of loading for all DSM-5 AUD (> 0.6). McBride et al. (2011) also found a better structure in the one-dimensional model in an Australian sample, finding high values of

Drug Alcohol Depend. Author manuscript; available in PMC 2016 July 01. 
loadings (> 0.6) in all criteria of the DSM-5 AUD, which was also the case of Shmulewitz et al. (2010) using an Israeli sample. Considering that the Craving criterion was not included in the three studies above-cited (Kuerbis et al., 2013; McBride et al., 2011; Shmulewitz et al., 2010) our study was the second to validate the inclusion of this criterion within the DSM-5 AUD, in a non-U.S. large representative sample, and the first in a middle-income country. As stated by some authors (Keyes et al., 2011; Pombo et al., 2014; Courtney and Ray, 2014; Leggio, 2009), the support for the validity of craving as a component of alcohol addiction also comes from other research fields such as behavioral research, imaging, pharmacology, and genetic epidemiology.

Our IRT model findings are presented in a very similar fashion to the findings presented in previous studies with large U.S. samples (Saha et al., 2006; Casey et al., 2012; Edwards et al., 2013). Regarding discrimination, the positioning of the criteria Given Up and Time Spent with the smallest (Saha et al., 2006; Casey et al., 2012) and Hazardous Use with the lowest (Saha et al., 2006; Edwards et al., 2013) value, has already been found. Concerning severity, our study confirmed the consensus of the lowest value for Larger/Longer (Saha et al., 2006; Casey et al., 2012; Edwards et al., 2013) and the smallest value for Given Up (Saha et al., 2006; Casey et al., 2012).

In testing DCF, we observed that in our sample, few criteria have measurement bias. Particularly Withdrawal and Quit/Control suffered direct effects from socio-demographic variables. These results are in line with previous findings of few DCF over the 11 criteria of DSM-5 AUD, and over the unidimensional factor, as stated by the DSM-5 Substance Use Disorders workgroup (Hasin et al., 2013). Perhaps, the most problematic subgroup for the diagnosis of DSM-5 AUD in São Paulo Metropolitan Area would be women, considering that this was the only variable which had direct effects both at the criterion- and factor-level, following the Saha et al. rationale (2007). This can be a problem for this group, in which a lower level of scores on the DSM-5 AUD may be derived from a systematic lower fulfillment of the Withdrawal criterion, what can reflect a neurobiological gender difference in the vulnerability to alcohol withdrawal (Sharrett-Field et al., 2013). Our findings contradict the non-evidence of DCF between subgroups at the factor-level found by Saha et al. (2007) in a study in nationally representative sample of the U.S. adult population. Further studies investigating DCF on the unidimensional model total score level in other samples using MIMIC models are needed.

Regarding criterion-level DCF, our findings are in line with those from previous DCF studies with U.S. (Casey et al., 2012) and Thai (Srisurapanont et al., 2012) samples. These two studies also found a direct effect of age in Quit/Control (Casey et al., 2012;

Srisurapanont et al., 2012). Similarly to the study with the Thai sample (Srisurapanont et al., 2012), we also found direct effects of gender and age on Withdrawal. Unfortunately, both these studies did not test DCF at the DSM-5 AUD factor-level. Rose et al. (2012) and Kuerbis et al. (2013) also tested DCF on the DSM-5 AUD, but they examined this in samples that were either younger (Rose et al., 2012) or older (Kuerbis et al., 2013) than our sample, making it very difficult to compare the results. We were not able to find any other study that tested for the direct effects of marital status and employment in the DSM-5 AUD.

Drug Alcohol Depend. Author manuscript; available in PMC 2016 July 01. 
Our findings should be discussed in the light of the Brazilian context. Despite important differences as regards socio-economic indicators between Brazil and the U.S. (World Bank, 2014), it is interesting to note the similarities in the profile of DSM-5 AUD criteria endorsement in the general population of these two countries, despite the particularities found in relation to alcohol use in the metropolitan area of São Paulo recently (Silveira et al., 2011, 2012, 2014). Based upon data from this sample, our research group has reported a convergence for alcohol problems between genders (Silveira et al., 2012), the importance of low education in the development and non-remittance of AUD (Silveira et al., 2011), and a geographical location of regular alcohol use in neighborhoods of greater social deprivation (Silveira et al., 2014). In addition, we also found a large "use in larger amounts" class among past-year weekly alcohol users in this geographic area (Castaldelli-Maia et al., 2014). This becomes very important in view of the recent availability of the new edition of DSM-5 in Brazilian Portuguese (Manual Diagnósico e Estatístico de Transtornos Mentais, 2014). Interestingly, we did not find DCF from low educational and low-income level variables, an important result that support the DSM-5 use in these subpopulations with higher chance for development and no remission of AUD (Silveira et al., 2011) and regular use of alcohol (Silveira et al., 2014) in São Paulo Metropolitan Area. On the other hand, there is a call to the lower score on the DSM-5 AUD among women in this area - a subpopulation in which heavy episodic and frequent drinking are reaching the same levels as those found in men (Silveira et al., 2012). Finally, we found no direct effect on Larger/Longer criterion, which was the most endorsed criterion in our sample (almost a quarter of past-year alcohol users) as shown in our previous report (Castaldelli-Maia et al., 2014).

Limitations are noted. In Brazil, as in several other countries (Srisurapanont et al., 2012; Fazzino et al., 2014; Murphy et al., 2014), females drink less than males and there were fewer females than males in our analyses of criteria parameters and tests of DCF. Despite the smaller number of females as compared to males, we were able to find consistent DCF both in criterion- and factor-level by gender and there were no large 95\% CIs in the female subsample included in this study. Future research should nevertheless oversample females for specific analyses on some of the alcohol use disorder symptoms that are less frequent. The sample covers the community residents of a large urbanized area in Brazil, which precludes the generalization of our findings to the Brazilian general population who lives in rural settings, or to institutionalized or homeless individuals. Criteria data are based on self-report only, which should be seen both as strength and weakness, being the standard procedure for data collection in previous studies (Borges et al., 2010; Keyes et al., 2011; Kuerbis et al., 2013). Another limitation refers to the number (eleven) of disaggregated individual criterion items considered in the EFA, IRT, and DCF models, that could have occurred in different time-points in a respondent's lifetime, such as in previous studies (Borges et al., 2010; McBride et al., 2011).

Despite these limitations, this is the first population-based study on a developing country that tested the validity of the one-dimensional structure of the DSM-5 AUD criteria using the full set of 11 criteria in an urban population of South America. Similarly to previous studies conducted in the U.S., Given Up and Time Spent have high levels of severity and discrimination, respectively, and Larger/Longer and Hazardous Use have low levels of severity and discrimination, respectively. As one of the few studies that have evaluated DCF 
on the DSM-5 AUD, our results point to a small number of direct effects of sociodemographic variables on Withdrawal and Quit/Control at the criterion-level. More research is needed to evaluate measurement bias of the DSM-5 AUD criteria in different cultural settings and sociodemographic contexts.

\section{Supplementary Material}

Refer to Web version on PubMed Central for supplementary material.

\section{Acknowledgments}

\section{Role of Funding Source}

The São Paulo Megacity Mental Health Survey was funded by the State of São Paulo Research Foundation, Brazil (FAPESP Grant 03/00204-3, http://www.fapesp.br/materia/176/projeto-tematico/projeto-tematico.htm). Instrument development was supported by the Foundation for Science and Technology of Vitoria, Espírito Santo, Brazil (Fundo de Apoio à Ciência e Tecnologia do Município de Vitória - FACITEC 002/2003). Data analysis was supported by FAPESP Grant 2011/50517-4. Dr. Martins is currently supported by NIH-NICHD 1R01HD060072.

The São Paulo Megacity Mental Health Survey is carried out in conjunction with the World Health Organization World Mental Health (WMH) Survey Initiative. The authors thank the WMH staff for assistance with instrumentation, fieldwork, and data analysis. The main coordination center activities, at Harvard University, were supported by the United States National Institutes of Mental Health (R01MH070884), the John D. and Catherine T. MacArthur Foundation, the Pfizer Foundation, the US Public Health Service (R13-MH066849, R01-MH069864, and R01 DA016558), the Fogarty International Center (FIRCA R03-TW006481), the Pan American Health Organization, the Eli Lilly and Company Foundation, Ortho-McNeil Pharmaceutical, Inc., GlaxoSmithKline, Bristol-Myers Squibb, and Shire. The authors declare that the funders of the SPMHS had no role in study design, data collection and analysis, decision to publish, or preparation of the manuscript. The authors also declare that the commercial funders of the Harvard coordination center had no role in study design, data collection and analysis, decision to publish, or preparation of the manuscript.

\section{References}

American Psychiatric Association. Diagnostic and Statistical Manual of Mental Disorders. 5. American Psychiatric Association; Arlington, VA: 2013.

Agrawal A, Heath AC, Lynskey MT. DSM-IV to DSM-5: the impact of proposed revisions on diagnosis of alcohol use disorders. Addiction. 2011; 106:1935-1943. [PubMed: 21631621]

Blanco C, Rubio J, Wall M, Wang S, Jiu CJ, Kendler KS. Risk factors for anxiety disorders: common and specific effects in a national sample. Depress Anxiety. 2014; 31:756-764. [PubMed: 24577934]

Borges G, Ye Y, Bond J, Cherpitel CJ, Cremonte M, Moskalewicz J, Swiatkiewicz G, Rubio-Stipec M. The dimensionality of alcohol use disorders and alcohol consumption in a cross-national perspective. Addiction. 2010; 105:240-254. [PubMed: 20078482]

Casey M, Adamson G, Shevlin M, McKinney A. The role of craving in AUDs: dimensionality and differential functioning in the DSM-5. Drug Alcohol Depend. 2012; 125:75-80. [PubMed: 22516145]

Castaldelli-Maia JM, Bhugra D, de Andrade AG, Lotufo-Neto F. Substance use and misuse in Brazilian movies (2000-2008). Subst Use Misuse. 2013; 48:248-257. [PubMed: 23302060]

Castaldelli-Maia JM, Bhugra D. Investigating the interlinkages of alcohol use and misuse, spirituality and culture - Insights from a systematic review. Int Rev Psychiatry. 2014; 26:352-367. [PubMed: 24953154]

Castaldelli-Maia JM, Silveira CM, Siu ER, Wang YP, Milhorança IA, Alexandrino-Silva C, Borges G, Viana MC, Andrade AG, Andrade LH, Martins SS. DSM-5 latent classes ofalcoholusers in a population-basedsample: results from the São Paulo Megacity Mental Health Survey, Brazil. Drug Alcohol Depend. 2014; 136:92-99. [PubMed: 24440273]

Courtney KE, Ray LA. Subjective responses to alcohol in the lab predict neural responses to alcohol cues. J Stud Alcohol Drugs. 2014; 75:124-135. [PubMed: 24411804] 
Edwards AC, Gillespie NA, Aggen SH, Kendler KS. Assessment of a modified DSM-5 diagnosis of alcohol use disorder in a genetically informative population. Alcohol Clin Exp Res. 2013; 37:443451. [PubMed: 23347196]

Fazzino TL, Rose GL, Burt KB, Helzer JE. Comparison of categorical alcohol dependence versus a dimensional measure for predicting weekly alcohol use in heavy drinkers. Drug Alcohol Depend. 2014; 136:121-126. [PubMed: 24485060]

Haro JM, Arbabzadeh-Bouchez S, Brugha TS, de Girolamo G, Guyer ME, Jin R, Lepine JP, Mazzi F, Reneses B, Vilagut G, Sampson NA, Kessler RC. Concordance of the Composite International Diagnostic Interview Version 3.0 (CIDI 3.0) with standardized clinical assessments in the WHO World Mental Health surveys. Int J Methods Psychiatr Res. 2006; 15:167-180. [PubMed: 17266013]

Hasin DS, Beseler CL. Dimensionality of lifetime alcohol abuse, dependence and binge drinking. Drug Alcohol Depend. 2009; 101:53-61. [PubMed: 19095379]

Hasin DS, O’Brien CP, Auriacombe M, Borges G, Bucholz K, Budney A, Compton WM, Crowley T, Ling W, Petry NM, Schuckit M, Grant BF. DSM-5 criteria for substance use disorders: recommendations and rationale. Am J Psychiatry. 2013; 170:834-851. [PubMed: 23903334]

Keyes KM, Krueger RF, Grant BF, Hasin DS. Alcohol craving and the dimensionality of alcohol disorders. Psychol Med. 2011; 41:629-640. [PubMed: 20459881]

Krueger RF, Nichol PE, Hicks BM, Markon KE, Patrick CJ, Iacono WG, McGue M. Using latent trait modeling to conceptualize an alcohol problems continuum. Psychol Assess. 2004; 16:107-119. [PubMed: 15222807]

Kuerbis AN, Hagman BT, Sacco P. Functioning of alcohol use disorders criteria among middle-aged and older adults: implications for DSM-5. Subst Use Misuse. 2013; 48:309-322. [PubMed: 23373632]

Leggio L. Understanding and treating alcohol craving and dependence: recent pharmacological and neuroendocrinological findings. Alcohol Alcohol. 2009; 44:341-352. [PubMed: 19451661]

Manual Diagnósico e Estatístico de Transtornos Mentais. American Psychiatric Association. 5. Artmed; Porto Alegre: 2014.

McBride O, Teesson M, Baillie A, Slade T. Assessing the dimensionality of lifetime DSM-IV alcohol use disorders and a quantity-frequency alcohol use criterion in the Australian population: a factor mixture modelling approach. Alcohol Alcohol. 2011; 46:333-341. [PubMed: 21310744]

Mewton L, Slade T, McBride O, Grove R, Teesson M. An evaluation of the proposed DSM-5 alcohol use disorder criteria using Australian national data. Addiction. 2011; 106:941-950. [PubMed: 21205055]

Murphy CM, Stojek MK, Few LR, Rothbaum AO, Mackillop J. Craving as an alcohol use disorder symptom in DSM-5: an empirical examination in a treatment-seeking sample. Exp Clin Psychopharmacol. 2014; 22:43-49. [PubMed: 24490710]

Pombo S, Ferreira J, Cardoso JM, Ismail F, Levy P, Bicho M. The role of 5-HTTLPR polymorphism in alcohol craving experience. Psychiatry Res. 2014; 218:174-179. [PubMed: 24794154]

Rehm J, Rehn N, Room R, Monteiro M, Gmel G, Jernigan D, Frick U. The global distribution of average volume of alcohol consumption and patterns of drinking. Eur Addict Res. 2003; 9:147156. [PubMed: 12970583]

Rose JS, Lee CT, Selya AS, Dierker LC. DSM-IV alcohol abuse and dependence criteria characteristics for recent onset adolescent drinkers. Drug Alcohol Depend. 2012; 124:88-94. [PubMed: 22236537]

Sacco P, Torres LR, Cunningham-Williams RM, Woods C, Unick GJ. Differential item functioning of pathological gambling criteria: an examination of gender, race/ethnicity, and age. J Gambl Stud. 2011; 27:317-330. [PubMed: 20623329]

Saha TD, Chou SP, Grant BF. Toward an alcohol use disorder continuum using item response theory: results from the National Epidemiologic Survey on Alcohol and Related Conditions. Psychol Med. 2006; 36:931-941. [PubMed: 16563205]

Saha TD, Stinson FS, Grant BF. The role of alcohol consumption in future classifications of alcohol use disorders. Drug Alcohol Depend. 2007; 89:82-92. [PubMed: 17240085]

Drug Alcohol Depend. Author manuscript; available in PMC 2016 July 01. 
Sharrett-Field L, Butler TR, Reynolds AR, Berry JN, Prendergast MA. Sex differences in neuroadaptation to alcohol and withdrawal neurotoxicity. Pflugers Arch. 2013; 465:643-654. [PubMed: 23559099]

Shmulewitz D, Keyes K, Beseler C, Aharonovich E, Aivadyan C, Spivak B, Hasin D. The dimensionality of alcohol use disorders: results from Israel. Drug Alcohol Depend. 2010; 111:146-154. [PubMed: 20537809]

Silveira CM, Siu ER, Wang YP, Viana MC, Andrade AG, Andrade LH. Gender differences in drinking patterns and alcohol-related problems in a community sample in São Paulo, Brazil. Clinics. 2012; 67:205-212. [PubMed: 22473399]

Silveira CM, Siu ER, Martins SS, Anthony JC, Saito LP, Andrade AG, Kutschenko A, Viana MC, Wang YP, Andrade LH. Drinking patterns and alcohol use disorders in the sãopaulo megacity mental health survey, Brazil: gender differences, individual socioeconomic status and influences of neighborhood social deprivation. Plos One. 2014; 9:e108355. [PubMed: 25272008]

Silveira CM, Viana MC, Siu ER, de Andrade AG, Anthony JC, Andrade LH. Sociodemographic correlates of transitions from alcohol use to disorders and remission in the São Paulo megacity mental health survey, Brazil. Alcohol Alcohol. 2011; 46:324-332. [PubMed: 21414952]

Silveira CM, Wang YP, Andrade AG, Andrade LH. Heavy episodic drinking in the São Paulo epidemiologic catchment area study in Brazil: gender and sociodemographic correlates. J Stud Alcohol Drugs. 2007; 68:18-27. [PubMed: 17149514]

Srisurapanont M, Kittiratanapaiboon P, Likhitsathian S, Kongsuk T, Suttajit S, Junsirimongkol B. Patterns of alcohol dependence in Thai drinkers: a differential item functioning analysis of gender and age bias. Addict Behav. 2012; 37:173-178. [PubMed: 22001084]

Viana MC, Teixeira MG, Beraldi F, Bassani IS, Andrade LH. Sao Paulo Megacity Mental Health Survey - a population-based epidemiological study of psychiatric morbidity in the Sao Paulo metropolitan area: aims, design and field implementation. Rev Bras Psiquiatr. 2009; 31:375-386. [PubMed: 20098829]

Woods CM. Empirical selection of anchors for tests of differential item functioning. Appl Psychol Meas. 2009; 33:42-57.

World Bank. [Acessed in April 24th, 2014] website http://data.worldbank.org/indicator 


\section{Highlights}

- The first full-set DSM-5 criteria population-based study on a developing country;

- Female was the most problematic subgroup for the diagnosis of DSM-5 AUD;

- Given Up and Time Spent had high levels of severity and discrimination;

- Larger/Longer had low level of severity but high level of discrimination. 

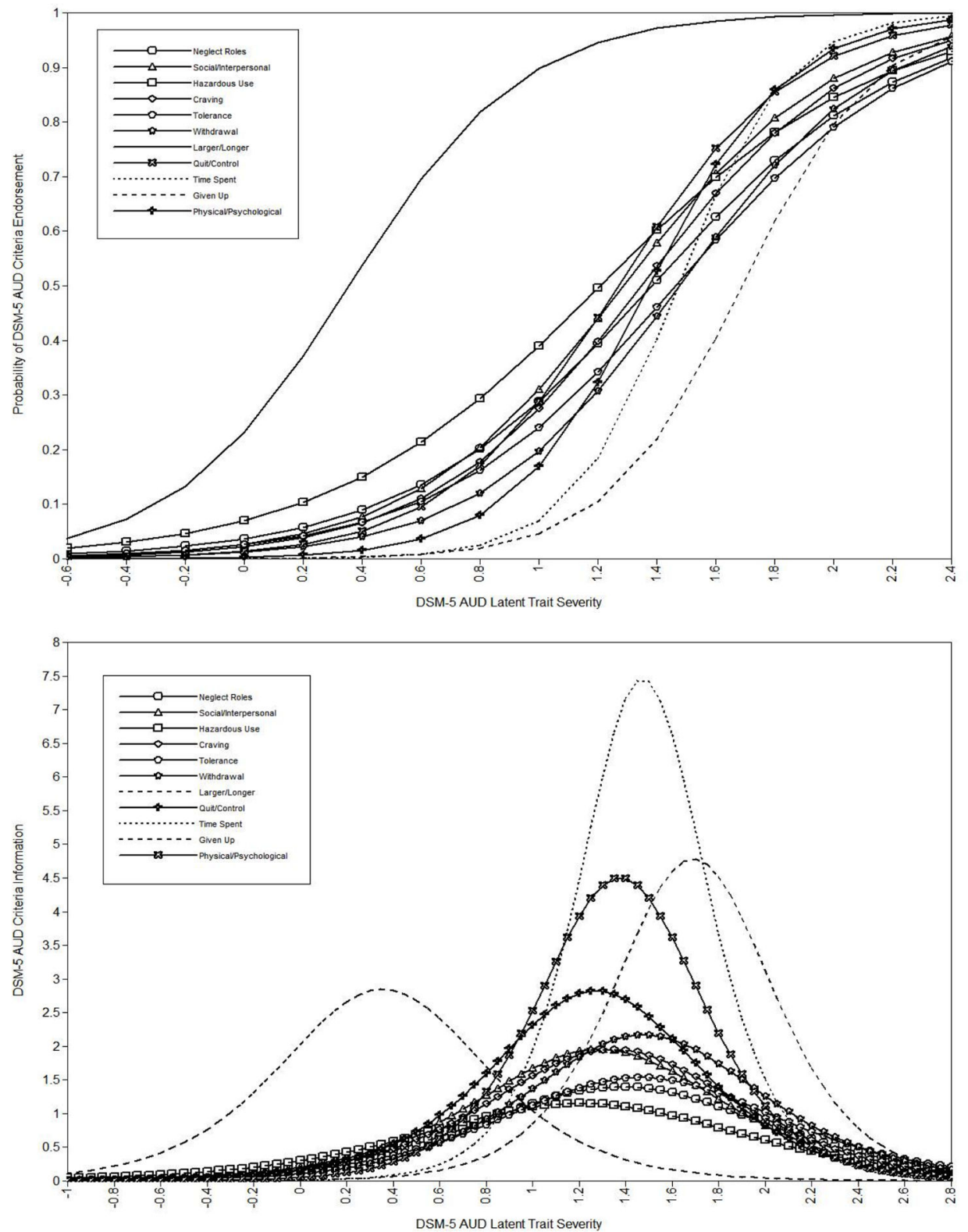

Figure 1.

Item Characteristics Curves (ICC) and Item Information Curves (IIC) of each criterion of DSM-5 Alcohol Use Disorder among alcohol users who had at least 1 drink/week in the past year in São Paulo Metropolitan Area, 2005-2007. 


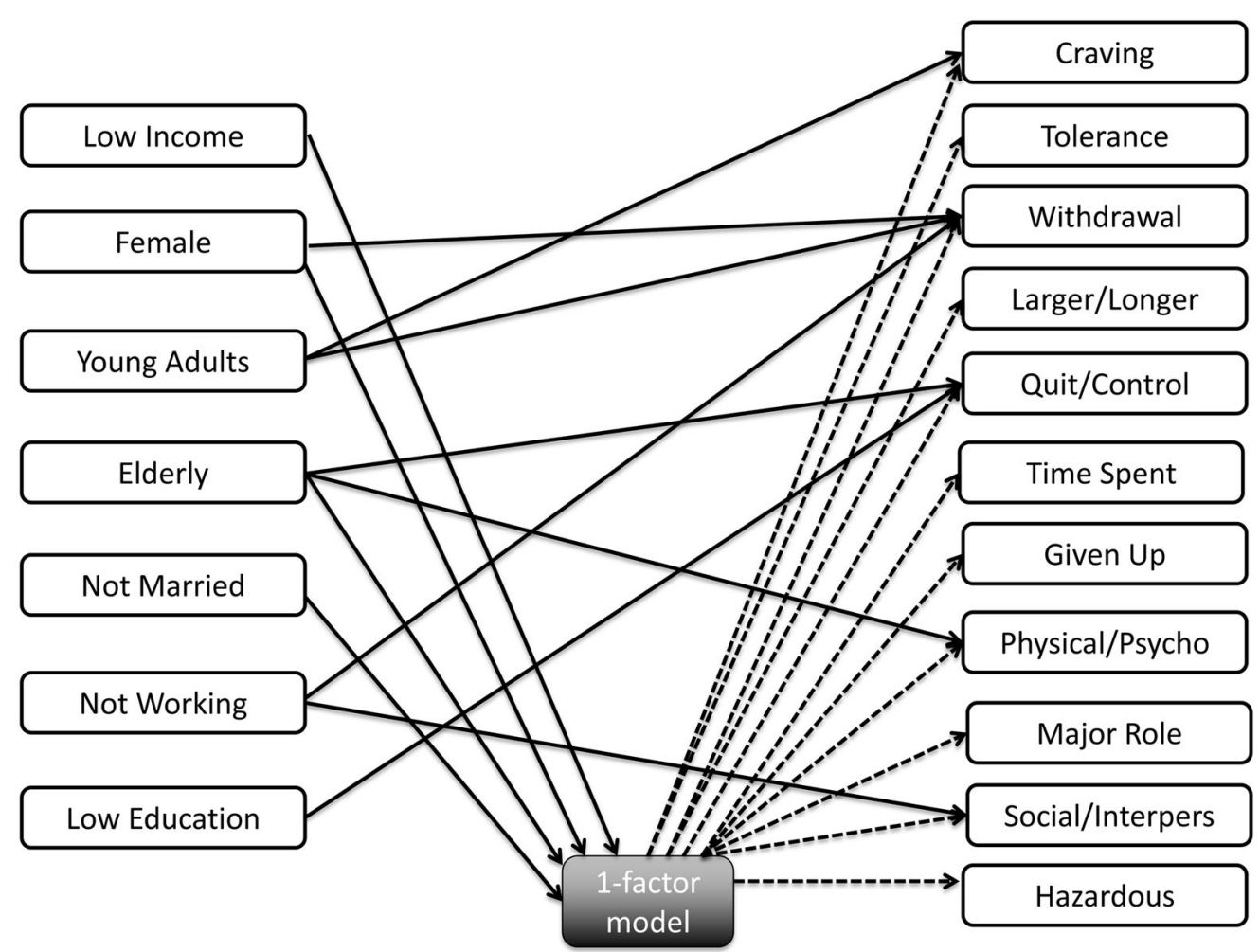

Figure 2.

Direct effects of sociodemographic correlates in DSM-5 AUD found in DCF models among alcohol users who had at least 1 drink/week in the past year in São Paulo Metropolitan Area, 2005-2007. 


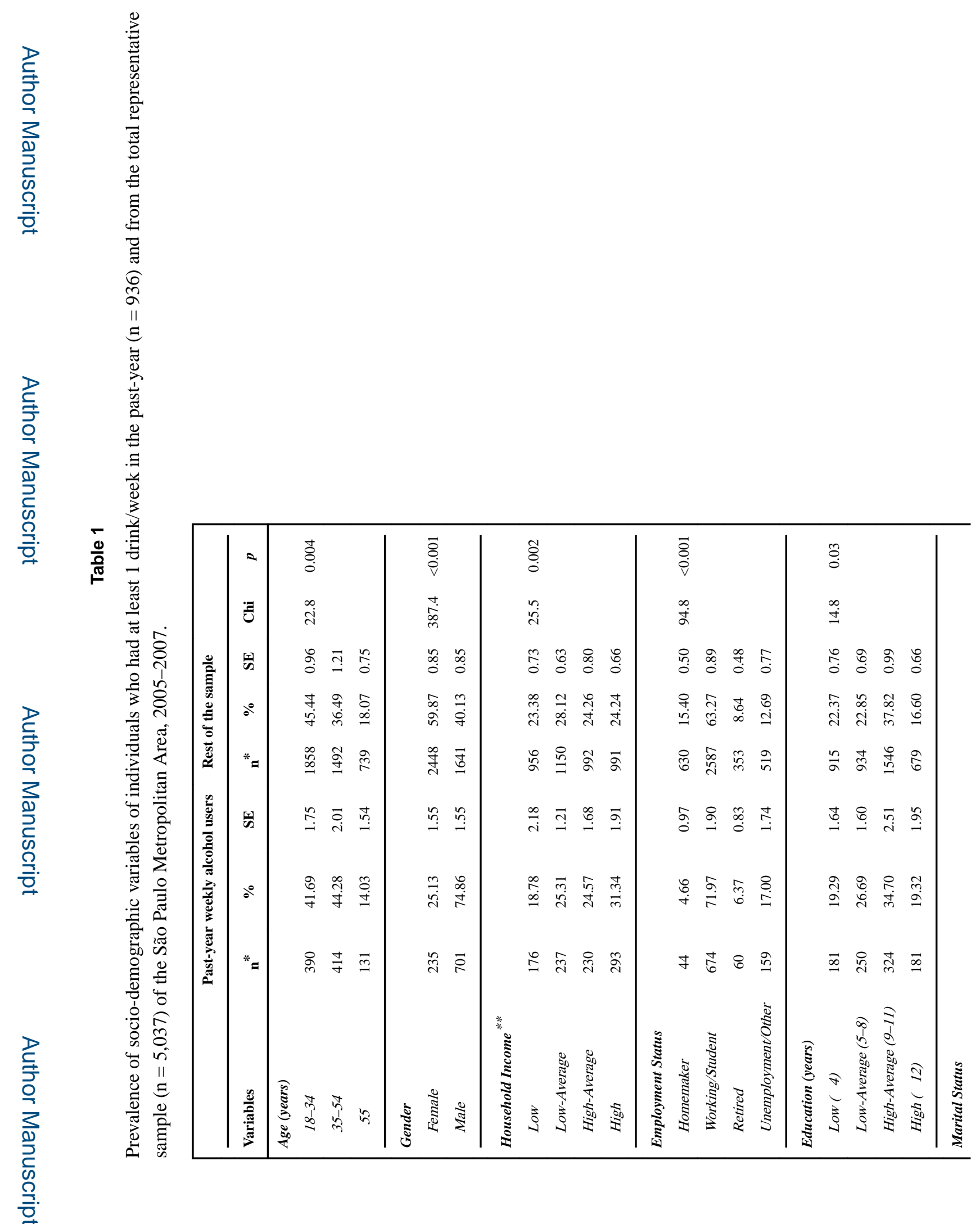

Drug Alcohol Depend. Author manuscript; available in PMC 2016 July 01. 


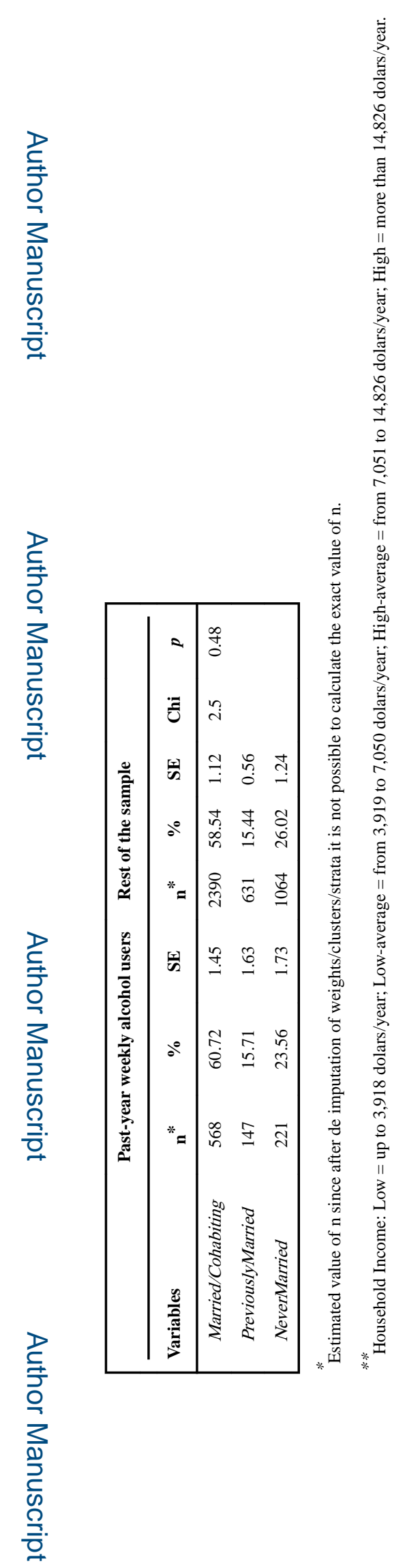

Drug Alcohol Depend. Author manuscript; available in PMC 2016 July 01. 


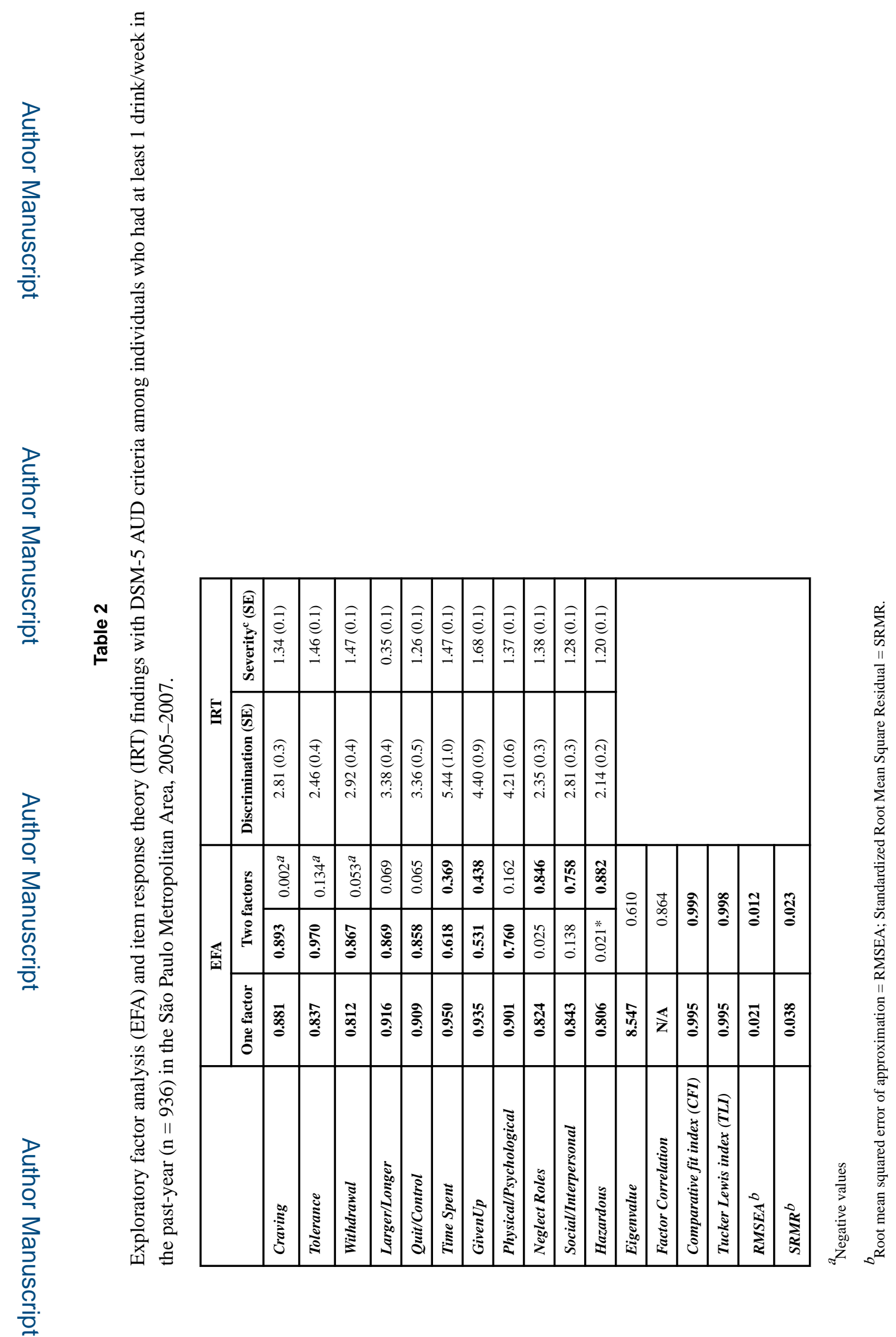

Drug Alcohol Depend. Author manuscript; available in PMC 2016 July 01. 


\section{Table 3}

Results of the final model of differential criteria functioning (DCF) per each sociodemographic correlates, which were considered for measurement bias on individuals who had at least 1 drink/week in the past-year (n = 936) in the São Paulo Metropolitan Area, 2005-2007.

\begin{tabular}{|c|c|c|c|c|}
\hline & Estimate & \multicolumn{2}{|c|}{$95 \% \mathrm{CI}$} & $\mathbf{p}$ \\
\hline \multicolumn{5}{|l|}{ DSM-5 AUD unidimensional factor } \\
\hline Female & -0.31 & -0.59 & -0.02 & 0.031 \\
\hline Young Adults (18-34 years) & 0.03 & -0.24 & 0.30 & 0.807 \\
\hline Elderly ( $\geq 55$ years) & -0.50 & -0.96 & -0.04 & 0.031 \\
\hline Not married & 0.26 & 0.05 & 0.47 & 0.014 \\
\hline Not working/studying & 0.10 & -0.16 & 0.37 & 0.446 \\
\hline Low educational level (Up to 8 years) & 0.20 & -0.05 & 0.45 & 0.120 \\
\hline Low income (Up to 7,050 US dollars/year) & 0.30 & 0.08 & 0.53 & 0.007 \\
\hline \multicolumn{5}{|l|}{ Social/Interpersonal } \\
\hline Female & -0.10 & -0.60 & 0.38 & 0.665 \\
\hline Young Adults (18-34 years) & -0.54 & -1.38 & 0.28 & 0.198 \\
\hline Elderly ( 255 years) & -0.53 & -1.58 & 0.52 & 0.324 \\
\hline Not married & -0.32 & -1.07 & 0.43 & 0.407 \\
\hline Not working/studying & 1.36 & 0.66 & 2.06 & $<0.001$ \\
\hline Low educational level (Up to 8 years) & -0.11 & -0.81 & 0.59 & 0.757 \\
\hline \multicolumn{5}{|l|}{ Craving } \\
\hline Female & -0.15 & -0.94 & 0.63 & 0.703 \\
\hline Young Adults (18-34 years) & -1.14 & -1.89 & -0.39 & 0.003 \\
\hline Elderly ( 255 years) & 0.82 & -0.33 & 1.99 & 0.162 \\
\hline Not married & 0.37 & -0.32 & 1.07 & 0.299 \\
\hline Not working/studying & 0.14 & -0.63 & 0.91 & 0.717 \\
\hline Low educational level (Up to 8 years) & 0.46 & -0.25 & 1.18 & 0.207 \\
\hline \multicolumn{5}{|l|}{ Withdrawal } \\
\hline Female & -1.34 & -2.35 & -0.32 & 0.010 \\
\hline Young Adults (18-34 years) & -1.00 & -1.92 & -0.08 & 0.032 \\
\hline Elderly ( 255 years) & 0.58 & -0.35 & 1.52 & 0.222 \\
\hline Not married & 0.51 & -0.18 & 1.20 & 0.151 \\
\hline Not working/studying & 0.96 & 0.20 & 1.73 & 0.013 \\
\hline Low educational level (Up to 8 years) & -0.17 & -1.00 & 0.66 & 0.690 \\
\hline \multicolumn{5}{|l|}{ Quit/Control } \\
\hline Female & 0.61 & -0.49 & 1.72 & 0.276 \\
\hline Young Adults (18-34 years) & -0.96 & -2.07 & 0.14 & 0.088 \\
\hline Elderly ( $\geq 55$ years $)$ & 1.43 & 0.10 & 2.75 & 0.034 \\
\hline Not married & 0.43 & -0.43 & 1.12 & 0.387 \\
\hline Not working/studying & -0.60 & -1.60 & 0.39 & 0.233 \\
\hline
\end{tabular}

Drug Alcohol Depend. Author manuscript; available in PMC 2016 July 01. 


\begin{tabular}{lcccc} 
& Estimate & \multicolumn{2}{c}{$\mathbf{9 5 \%}$ CI } & p \\
\hline Low educational level (Up to 8 years) & $\mathbf{1 . 1 1}$ & $\mathbf{0 . 1 3}$ & $\mathbf{2 . 0 8}$ & $\mathbf{0 . 0 2 6}$ \\
\hline Physical/Psychological & & & & \\
$\quad$ Female & -0.35 & -1.29 & 0.57 & 0.451 \\
$\quad$ Young Adults (18-34 years) & -0.54 & -1.70 & 0.61 & 0.359 \\
Elderly ( $\geq \mathbf{5 5}$ years) & $\mathbf{2 . 2 0}$ & $\mathbf{0 . 7 0}$ & $\mathbf{3 . 7 1}$ & $\mathbf{0 . 0 0 4}$ \\
Not married & -0.63 & -1.59 & 0.33 & 0.198 \\
Not working/studying & 0.32 & -0.66 & 1.31 & 0.518 \\
Low educational level (Up to 8 years) & -0.18 & -1.21 & 0.75 & 0.701 \\
\hline
\end{tabular}

